\title{
IDENTIFICACIÓN DE SERVICIOS PARA LA CONFORMACIÓN DE REDES DEL CORREDOR TURÍSTICO SOPÓ Y LA CALERA
}

\section{IDENTIFICATION OF SERVICES FOR THE CONFORMATION OF NETWORKS OF THE TOURIST CORRIDOR SOPO AND THE CALERA}

\author{
Álvaro Lamprea Delgado ${ }^{1}$ \\ María Concepción Salazar Alonso² \\ Adriana Posada Arrubla ${ }^{3}$ \\ William Zambrano Ayala ${ }^{4}$ \\ Jairo Vázquez Bernal ${ }^{5}$ \\ Doris Guerrero S ${ }^{6}$ \\ Jorge $\mathrm{H}$. Sandoval $\mathrm{T}^{\top}$
}

\section{RESUMEN}

En los municipios de La Calera y Sopó, en el Departamento de Cundinamarca - Colombia, el turismo se puede constituir en uno de los factores más importantes de

${ }^{1}$ Profesional en Comercio Internacional, Especialista en Gerencia de Mercadeo, Docente Investigador U.D.C.A. Dirección para correspondencia e-mail: alamprea@udca. edu.co

${ }^{2}$ Economista, Docente Investigador U.D.C.A. Dirección para correspondencia e-mail: masalazar@udca.edu.co

${ }^{3}$ Economista Agrícola M.Sc. Planeación Urbana y Regional, decana Ingeniería Comercial. U.D.C.A. Email: aposada@udca.edu.co

${ }^{4}$ Comunicador Social - Periodista M.Sc Comunicación. Docente Investigador Ingeniería Comercial. U.D.C.A. Email: zambrano_william@hotmail.com

${ }^{5}$ Mercadotecnista, Esp Gestión Social y Ambiental Docente Investigador Ingeniería Comercial U.D.C.A. Email: jvasquez@udca.edu.co Dirección para Correspondencia: Calle 222 No. 54-25, Bogotá, D.C.

${ }^{6}$ Abogada. Filosofa Docente Investigador. Ingenierìa Comercial U.D.C.A. Email: dorisgue@udca.edu.co

7 Economista-mercadotecnista M.Sc. Docencia Universitaria. Docente Investigador Ingenierìa Comercial. U.D.C.A. Email: jorhumsan@hotmail.com desarrollo y de crecimiento económico, mediante la generación de empleo y la distribución del ingreso. Las actividades y servicios turísticos que las empresas y la comunidad ofrecen a los turistas, no responde a intereses económicos únicamente, sino a las necesidades de diferentes grupos sociales, su identidad cultural, la biodiversidad de la región y el uso de los recursos naturales, entre otros aspectos a resaltar de los municipios. La consecución y el registro de la información primaria de las unidades representativas de las poblaciones objeto de estudio permitió generar una propuesta para la conformación de redes turísticas, a través de la creación de nodos, los cuales buscan satisfacer necesidades, sustentadas en los intereses de los municipios e impulsar sus potencialidades turísticas. También son dirigidas hacia un concepto amplio de turismo que involucre un número de posibilidades, enfatizando en la gestión ambiental que los municipios están desarrollando. Representan los nodos para esta investigación los usuarios de los servicios, las empresas y la comunidad en general. Se hacen necesarias las relaciones dadas por intercambios culturales, actividades y eventos entre otros y para incentivar el ecoturismo, debido a que éstas permiten detectar, vincular y relacionar diversos intereses, enfocados a satisfacer, desde diferentes perspectivas, las necesidades individuales y comunitarias, en los municipios mencionados. 
Palabras clave: Turismo, red social, ecoturismo, comunidad, servicios.

\section{SUMMARY}

In the municipalities of The Calera and Sopó, Department of Cundinamarca - Colombia, tourism could be one of the most important factors of rural development and economic growth that generate a positive impact by means of employment generation and income distribution. The activities and tourist services that enterprises and the community offer to the tourists, not only respond to economic interests, but also involve the necessities of the different social groups, their cultural identity, the biodiversity of the region and the use of the natural resources, among other outstanding aspects of the municipalities. The attainment and the registration of the primary information of representative population units, object of this study, such as tourists, community and companies, allowed the generation of a proposal for the conformation of a tourist network through the creation of nodes and connection points with a network. This, in order to satisfy necessities, sustained in the interests of the municipalities and to force the promotion of their tourist potentialities, directed toward a wider concept of tourism that involves a higher number of possibilities, emphasizing in the environmental administration that the municipalities are developing. Nodes are represented by the communities, the users of the services, enterprises and the community in general. Relationships given by cultural exchanges, activities and events, among others, and the motivation for an ecotourism, allowed to detect, to connect, and to relate diverse interests, focused to satisfy from different perspectives the individual and community necessities in the aforementioned municipalities.

Key words: Tourism, social network, ecotourism, community, services.

\section{INTRODUCCIÓN}

Las redes y la creación de los servicios turísticos han evolucionado a lo largo de los siglos, según el desarrollo del sector. Mazón (2001) quien plantea el desarrollo del turismo por etapas, la primera, ubicada a partir del siglo XVI y que se extiende hasta el inicio de la primera guerra mundial, donde sólo los más ricos y poderosos podían disfrutar del turismo. La otras etapas finalizan en la actualidad y hacen énfasis en el ecoturismo.

En Centroamérica, se destacan como impulsadores de la industria ecoturística Costa Rica, México, Nicaragua, Panamá, Honduras y el Caribe, específicamente, República Dominicana y Cuba. La experiencia turística en Costa Rica demuestra la existencia de una vía alternativa para el desarrollo económico que valoriza el medio ambiente y, en particular, los recursos naturales, como capital natural con plena capacidad de generar riqueza. El uso de un modelo integral de ecoturismo imprimió una dirección muy particular al sector, no sólo en Costa Rica y en el Continente americano, sino a nivel mundial y cambió rápidamente los conceptos tradicionales, ruta, circuito o corredor turístico (Churchil, 2003).

De acuerdo al mismo autor, el modelo adoptado desarrolló productos, tales como el de observación de aves, en el que se utilizaba un área natural, usualmente un parque nacional, con un trazado básico de sendero por donde caminar y un guía especializado capaz de interpretar, para el turista, el medio natural. En consecuencia, las comunidades nativas, cercanas a los atractivos, se convirtieron en los centros o pueblos de apoyo y es precisamente allí donde aparece el concepto de redes, de rutas naturales y de corredores turísticos, basado en la diversidad ecológica y riqueza natural de los países. Un ejemplo de ello es la red de los Cinco Volcanes integrados por las regiones de Upala, Guanacaste, Bagaces, Heredia y Rincón de la Vieja, incluyendo en el corredor el "Volcán Rincón de la Vieja, el Volcán Turrialba, el Volcán Poas, el Volcán Iraza y el Volcán Arenal”.

En Nicaragua, el turismo desde el año 2000, se incorporó como uno de los ejes principales de desarrollo del país, por medio de los denominados conglomerados o cluster, conformados por las empresas prestadoras de servicios turísticos, la superestructura y los atractivos turísticos. Lo anterior debido a que, actualmente, se consideran las áreas naturales y especialmente los parques y otras áreas protegidas, con sus paisajes, flora y fauna silvestres, incorporado a aquellos rasgos culturales que puedan estar allí presentes, como atracciones notables para los habitantes de los países europeos y para los turistas de todo el mundo (Gutiérrez Roa, 2000). En México, se destacan algunos circuitos y regiones, las cuales tienen un particular interés ecoturístico, como son La Península de Baja California y Mar de Cortés, la 
Sierra Madre Occidental y Noroeste de México (Ceballos Lascourain, 1998).

Brasil es uno de los destinos con mayor potencial en ecoturismo, ya que posee uno de los íconos mundiales de la ecología y de la biodiversidad: la Amazonía, localizada al norte del país, con cerca de 5,5 millones de $\mathrm{km}^{2}$. Hace presencia la belleza natural con los 44 parques nacionales de protección a los ecosistemas, además que posee gran variedad de circuitos turísticos, entre los cuales, se destacan das Águas, das Grutas, que posee más de 100 municipios con grutas o sitios paleontológicos; das Serras, que revela grandes bellezas naturales, como grutas, valles y flores; Terras Altas da Mantiqueira; Pico da Bandeira y da Canastra (MINISTERIO DO TURISMO DO BRASIL, 2005).

Es así, como la concepción del turismo ha cambiado. Los académicos han tratado de definir el turismo alternativo como aquel, cuyo contacto y entendimiento entre las comunidades receptoras deben estar en armonía con el medio ambiente (Smith E Eadington, 1992, citados en Newsome, 2002).

Este concepto, se enfoca hacia el turismo de Sopó y La Calera, objeto de esta investigación, coherente con la naturaleza, los valores sociales y comunitarios, que permiten una relación de beneficio entre locales y turistas.

Otras características de este tipo de turismo son los menores impactos sobre el medio ambiente y la complementariedad con sectores, como la agricultura y la artesanía, la relación entre el turismo con las comunidades y el medio ambiente es cada vez más estrecha. Debido al crecimiento de la demanda por servicios y/o productos turísticos, el oferente busca la satisfacción de necesidades e identifica problemas relacionados, como el medio ambiente, el uso de la tierra y el impacto en la fauna y los ecosistemas ocasionados por los viajes (Pérez de las Heras, 2004). Conceptúa el mismo autor que frente a estos problemas, se tienen los beneficios tangibles del turismo, en mejores ingresos y contribución al desarrollo económico de los municipios e intangibles, como educación, sensibilización y políticas claras que protejan los recursos naturales.

La creación de redes sociales, a través de las rutas, corredores y circuitos turísticos en Centro y Sur América, han alcanza un mayor desarrollo en las comunidades locales, al encontrar soluciones grupales para lograr mayores beneficios económicos y sociales. Se concibe por red social el espacio de diálogo y coordinación, a través del cual se vinculan organizaciones sociales e instituciones públicas y privadas, en función de un objetivo común, sobre la base de normas y valores compartidos, en virtud del principio de reciprocidad, en términos de un proceso de estabilización, adaptación y control (Lommitz, 1994) y formadas por nodos entendidos éstos como los representantes de las comunidades y las relaciones y los intercambios que se dan entre los actores (Ritzer, 2001).

Teniendo en cuenta lo anterior a principios del 2003 en los Estado Unidos, se crean varios sitios de redes sociales, entre ellos el Emode. El sitio más antiguo, como red social es "Friendster", con más de 3.000 millones de usuarios en línea, que para junio del 2004, se habían inscrito más de 800.000 personas para organizar eventos especiales, incluyendo 250 temas en más de 600 ciudades (Lamb \& Hair, 2006).

En Bélice, México y Estados Unidos, se implementan redes sociales en torno a la migración, consistente en lazos que vinculen comunidades remitentes y puntos específicos de destino en las sociedades receptoras, nexos que unen a los migrantes dentro de una serie de relaciones sociales complementarias e interpersonales y que se sostienen gracias a un conjunto informal de experiencias y conductas ordenadas (Pablos, 2001).

Durante los años noventa, se impuso la apreciación de estar en el principio de la era planetaria, no solo por la unión que permiten las redes electrónicas, por los efectos de la crisis financiera o por los efectos ambientales, sino por el espacio global, donde el consumo crea la espejismo de pertenecer a un mundo interconectado no solamente por redes económicas o rutas turísticas, sino por la posibilidad de compartir las expresiones culturales, las religiosas, las gastronómicas y los paisajes naturales (Bejar, 2007).

En la Cumbre Mundial de Ecoturismo, celebrada en Québec, Canadá 2002, se recalcó que América es probablemente una de las regiones del mundo donde el ecoturismo se está desarrollando con mayor rapidez. Se demostró "la participación de las comunidades locales; la necesidad de programas accesibles para todas las 
personas y la necesidad de planes estratégicos a través de la creación, implementación y desarrollo de redes, rutas y corredores turísticos" (Guzmán, 2005).

Teniendo en cuenta lo anteriormente planteado, en Colombia se han creado o proyectado 52 rutas o corredores turísticos, entre ellos: Macondo, en el Magdalena; los 50 años del Folklor, entre Bogotá - Espinal y Neiva; Cantores de la Provincia, entre Valledupar y Santa Marta; la ruta del Bambuco y el paisaje Arqueológico entre Bogotá y San Agustín; la tradición Cafetera en el Quindío, Risaralda y Caldas (Jany, 2001).

Los municipios de Sopó y la Calera, ubicados en el departamento de Cundinamarca, corazón de Colombia y su centro geográfico que es la Sabana de Bogotá, sirven principalmente a la población de la capital, como centro de recreación y esparcimiento.

Las actividades turísticas que realizan las empresas y la comunidad y que son brindadas a los turistas en los municipios objeto de estudio, no responden exclusivamente a intereses económicos, sino que también obedecen a las necesidades de las comunidades locales, como afianzar y dar a conocer sus manifestaciones artísticas, resaltando la identidad cultural, la biodiversidad, la variedad de costumbres, gastronomía, uso de los recursos naturales y sus valores de dichos municipios (Abravel, 1992).

Por lo anterior, es importante sensibilizar a las poblaciones de los municipios de La Calera y Sopó, sobre el aprovechamiento de los atractivos naturales y de los recursos culturales para el desarrollo del ecoturismo, que se podrían convertir en ventajas comparativas y competitivas en el momento de ofrecer los productos y los servicios turísticos.

Es evidente que las ventajas mencionadas no serán suficientes para competir en el exigente mercado del turismo local y nacional; se requiere de nuevas formas, procesos y estrategias, planes para desarrollar y proyectar el turismo, por lo que se propone la creación de redes sociales.

La participación comunitaria es fundamental para construir el tejido social que organice los servicios de las redes turísticas en La Calera y Sopó, que genere desarrollo y bienestar socio-económico real en las comunidades, además, de las relaciones directas entre el sector con la biodiversidad, el ambiente y la forma como las comunidades interactúan con su entorno, pues las personas son las únicas poseedoras de la cultura y deben procurar sostener su riqueza natural, ecológica y cultural en el corto, mediano y largo plazo (Bacca Urbina, 2002).

Teniendo como referente la propuesta de creación de redes para el desarrollo del turismo y el ecoturismo y analizada la problemática generada en ellos y su impacto en el desarrollo de un país y, por ende, en sus localidades, se propuso en la investigación identificar los servicios turísticos de los municipios de Sopó y la Calera para la conformar redes sociales del corredor turístico de estos dos municipios.

\section{MATERIALES Y MÉTODOS}

La investigación buscó determinar cuáles servicios y/o productos turísticos se pueden ofertar a través de la creación de redes en los Municipios de Sopó y La Calera.

Siendo la exploración de orden social y de carácter cualitativa, se realizaron estrategias metodologícas, como entrevistas en profundidad y aplicación de la Escala de Likert (Likert, 1932, citado por Ospina et al. 2005), la cual determinó la reacción de los sujetos sobre la posibilidad de crear redes turísticas que faciliten la interacción entre las comunidades y las empresas que desarrollan los servicios turísticos, en los municipios mencionados. El instrumento fue aplicado en las alcaldías municipales y sitios de afluencia turística y comunitaria, como los parques principales. En las empresas públicas y privadas, se llevaron a cabo estas estrategias en días laborales, lo que permitió determinar los servicios en gastronomía, ecología y cultural, turismo de aventura, turismo recreacional y agroturismo, para la estructuración de las redes (Hernández, 2003).

La población de los Municipios de Sopó y La Calera es de 43.415 habitantes. Según el Censo del año 2005, por el Departamento Administrativo Nacional de Estadísticas DANE (2007), se estratificó y organizó por categorías homogéneas; para las empresas públicas y privadas, la comunidad y los turistas (cuya población es infinita), se determinó la muestra, con un nivel de confianza del 95\% 
y reduciendo el error. Por lo anterior, se aplicó la formula (Núñez del Prado Benavente, 2000):

$\mathrm{n}=\mathrm{Z}^{2}(\mathrm{P}(1-\mathrm{P})) / \mathrm{e}^{2}$, donde

n: $\quad$ es la cantidad de encuesta a aplicar,

Z: es el nivel de confianza que se pueda estructurar las redes,

P: $\quad$ probabilidad de éxito de creación de las redes

(1- P): probabilidad de fracaso de crear las redes o error.

Se obtuvo, en Sopó, una muestra de 105 y para La Calera, 115, es decir, se realizaron un total de 220 encuestas a los turistas en los dos municipios; respecto a la comunidad, la muestra fue de 76 para Sopó y 76 para La Calera para 152 encuestas aplicadas. Finalmente, se ejecutaron en las empresas públicas y privadas 125 encuestas, 52 en Sopó y 73 en La Calera.

\section{RESULTADOS Y DISCUSIÓN}

Los municipios de La Calera y Sopó, por su cercanía geográfica a Bogotá, deben aprovechar la riqueza de sus recursos humanos, naturales, ecológicos, religiosos, gastronómicos y de turismo de ocio.

La escala de Likert permitió medir actitudes favorables o desfavorables respecto a los servicios y productos turísticos de los dos municipios. Se determinó que los atractivos de estos municipios son potencialmente aprovechables para ofrecerse a través de las redes turísticas, debido a que el $85 \%$ de los turistas que visitan los municipios de Sopó y La Calera, participarían en las actividades ecológicas, religiosas y gastronomicas, además, por que el $28,6 \%$ de los turistas visitarían los dos municipios por los atractivos turísticos que allí se hallan como. Pionono y la Plaza de los Tibas; el 21,7\%, por las ferias municipales; el $16,3 \%$, acude allí por las actividades ecológicas y el $10 \%$ por conocer los lugares religiosos, entre otras actividades, identificando así los principales servicios turísticos propuestos para la red.

Cada municipio tiene lugares llamativos; el parque de Pionono es considerado, por el 33,5\% de los turistas, como un atractivo, al igual que la represa de San Rafael, las Piedras de Tunjaque, la Panorámica de La Calera (Figura 1a) y el Cerro del Águila (Figura 1b), recursos turísticos que se agruparon como espacios para el diálogo y el desarrollo, a través de la conformación de las redes.
Otros recursos, como el Santuario del Señor de la Peña, la Iglesia de los Arcángeles (Figura 1c), el parque de la Corporación Autónoma Regional de Cundinamarca (CAR) son considerados por el $11,4 \%$ de los turistas, como los sitios más representativos de los poblados, además del Parque de la CAR (puente Sopó), la compañía de lácteos Alpina, la Hacienda Casa Blanca, el Parque Jaime Duque y la Represa de Chingaza, el Lago Parque de Sopó (Figura 1d) y los restaurantes, con los cuales, se conformaron la línea de productos y servicios a ofrecer, por medio de las redes.

Estos recursos pueden ser aprovechados por las comunidades y especialmente, por la través de la creación de redes organizadas, según los gustos y/o aficiones de las personas participantes, sirviendo como estrategia para seguir desarrollando el turismo en las zonas de interés y ser representativo en el desarrollo social, cultural y económico. Lo anterior es posible si se mejoran aspectos, tales como la falta de administración, la incipiente infraestructura turística, la capacitación de la comunidad en el tema, la preparación de ferias, el desconocimiento de la riqueza natural y ambiental que no han sido suficientemente aprovechas y, por consiguiente, permitiría optimizar los recursos al crearse redes sociales para impulsar el corredor turístico, en los municipios de Sopó y La Calera.

La conformación de las redes, se orientó hacia la optimización en el uso de los recursos naturales y servicios turísticos disponibles en las comunidades, dado el interés de los municipios de Sopó y La Calera por el impulso y promoción de sus potencialidades turísticas como un todo. Lograr la integración entre los diferentes miembros de estas comunidades de los municipios, en relación con las empresas es la adecuada optimización y utilización de los servicios turísticos en beneficio del usuario y de todos los miembros de la comunidad.

Por lo anterior, se propone orientar las redes hacia el concepto de turismo que involucre un sin número de posibilidades, destacando los aspectos naturales y ambientales que los municipios han desarrollado, por lo que se puede representar, dentro de las redes, uno o varios recursos. Los nodos, para tal fin, representarían el valor de sus espacios naturales, religiosos, artesanales o gastronómicos y las aristas, por las relaciones entre ellos, las cuales pueden ser distinto tipo, como intercambios culturales, de ferias, de eventos gastronómicos, de tal 

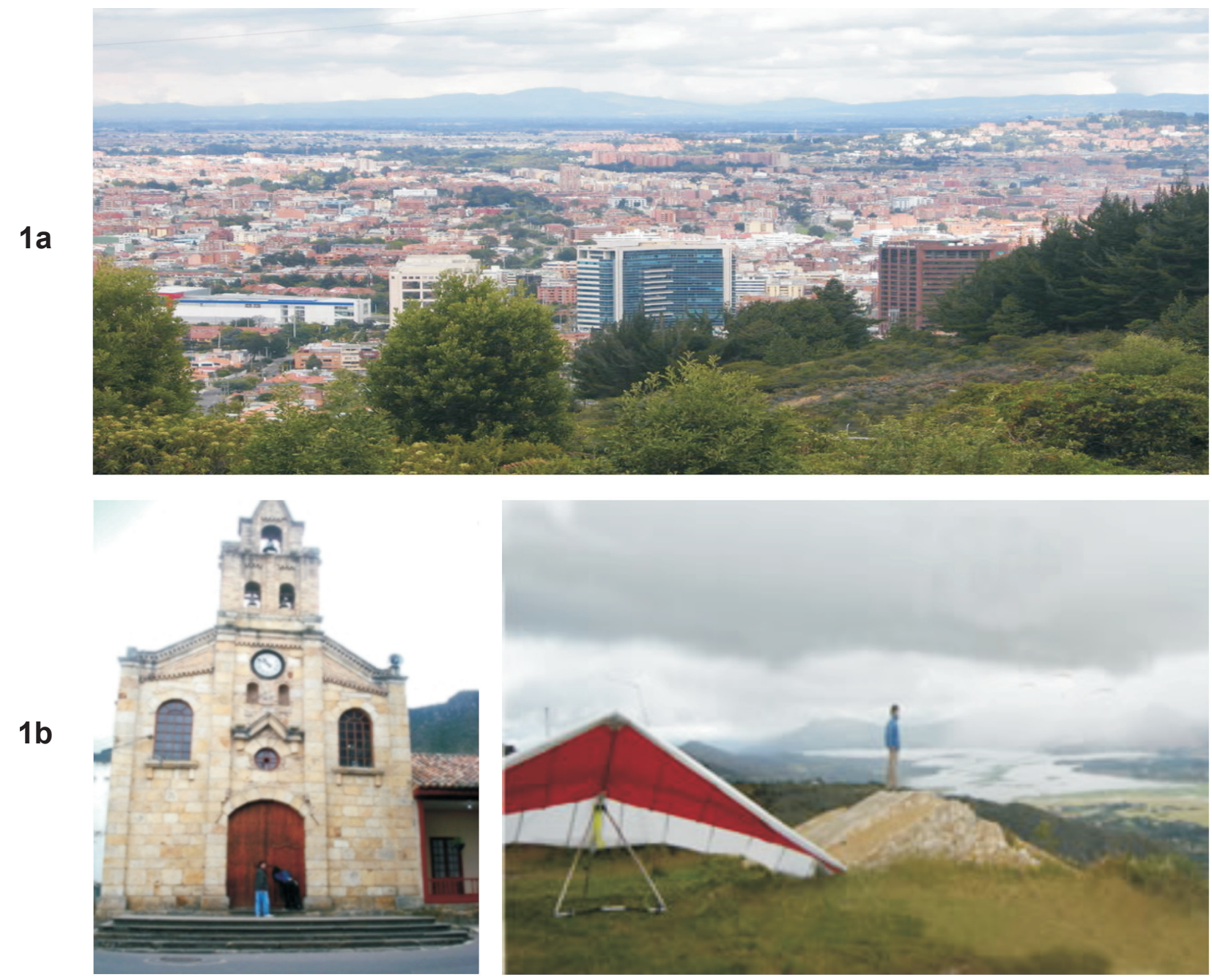

1c

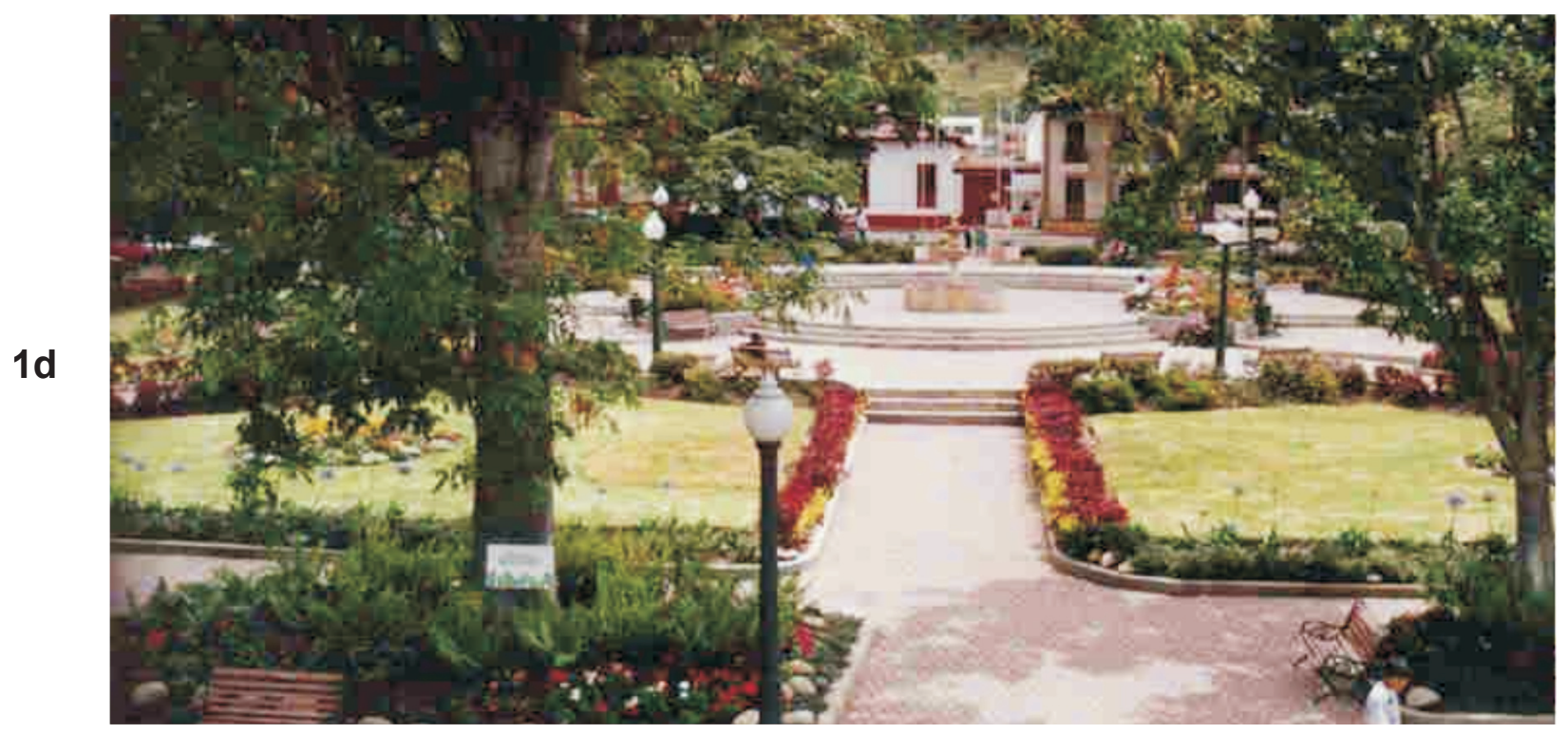

Figura 1. Algunos sitios de interés turístico en los municipios de La Calera y Sopó: 1a, Panorámica de La Calera; 1b, Cerro del Águila; 1c, La Iglesia de los Arcángeles; 1d Parque de Sopó 
manera que se fortalecerán las relaciones entre los municipios (Soares et al. 2006).

Para el caso del corredor, el diseño de redes y de las relaciones específicas de las variables, los elementos y los componentes, se inicia con los servicios básicos comunes, como son los gastronómicos, ecológicos, agro-turísticos, religiosos entre otros, permitiendo crear líneas de productos que se comercializan por medio de las redes sociales y mezcla de servicios durante el tiempo o recorrido por los atractivos que ofrecen los municipios a los turistas, a través del corredor La Calera - Sopó, como se observa en la Tabla 1. Con estos productos y sus líneas turísticas, se puede realizar una oferta variada, competitiva, atractiva y sostenible, permitiendo a las redes dinamizar el subsector que requiere de la creación de nuevas oportunidades turísticas.

Tabla 1. Servicios turísticos encontrados en los Municipios de Sopó y La Calera.

\begin{tabular}{|c|c|c|}
\hline Productos a ofrecer de manera unilateral & Línea de productos a ofrecer en la Red & Mezcla de productos \\
\hline $\begin{array}{l}\text { Gastronómicos: } \\
\text { Platos típicos } \\
\text { Postres } \\
\text { Comestibles varios } \\
\text { Ecológicos y culturales: } \\
\text { Visitas sitios de interés } \\
\text { Muestras artesanales } \\
\text { Turismo aventura: } \\
\text { Participación en: } \\
\text { Parapente, ciclo montañismo, ciclo rutas, montañismo. } \\
\text { Turismo recreacional: } \\
\text { Paseos, cabalgatas, ciclo paseos. } \\
\text { Agroturismo: } \\
\text { Visitas a granjas integrales }\end{array}$ & $\begin{array}{l}\text { A. Red } 1 \text { ecológico (Parques, Embalses, fincas } \\
\text { agroindustriales), religioso (Iglesias) } \\
\text { B. Red } 2 \text { ecológico (Parques, Embalses, fincas, } \\
\text { gastronómico (Restaurantes) } \\
\text { C. Red } 3 \text { ecológico (Parques, Embalses, fincas, } \\
\text { cabalgatas) } \\
\text { D. Red } 4 \text { ecológica (Parques, Embalses, fincas, } \\
\text { artesanal) } \\
\begin{array}{l}\text { E. Red5ecológica(Parques, Embalses, fincas religiosa } \\
\text { (Iglesias) y gastronómica (Restaurantes) }\end{array}\end{array}$ & $\begin{array}{l}\text { Servicios turísticos ya defi- } \\
\text { nidos en pro del bienestar de } \\
\text { la comunidad. } \\
\text { - Crédito } \\
\text { - Vivienda } \\
\text { - Salud } \\
\text { - Educación y otros }\end{array}$ \\
\hline
\end{tabular}

Una alternativa que permite dar valor agregado a los servicios turísticos de las redes es la combinación de los tipos de turismo, debido a que éstos ofrecen una variedad de alternativas para el disfrute, el descanso y la valoración de los recursos naturales, culturales, religiosos, entre otros, con que cuenta los municipios.

Las redes, se deberán crear a partir de procesos organizativos que implicarían no sólo el acceso a los bienes, servicios turísticos y ecoturísticos, sino a la integración comunitaria con los diferentes entes, como la comunidad, las universidades, las Organizaciones No gubernamentales ONGS, las agremiaciones, las cooperativas, las empresas públicas y privadas, que participaron en la investigación y que permiten conformar la propuesta de la cooperativa de trabajo asociado.
De otra parte, la conformación de las redes busca organizar y aprovechar, de forma competitiva y ambientalmente viable, los atractivos mencionados, de tal manera que se propicie el uso adecuado por parte de la comunidad, los turistas y de las organizaciones comunitarias, de espacios naturales.

Las redes, le apostarían al fortalecimiento del desarrollo ambiental, teniendo en cuenta que uno de los problemas del turismo es la relación con el deterioro del medio ambiente. La Comisión de Naciones Unidas para el Desarrollo Sostenible, con relación al turismo, ha recomendado la búsqueda de un turismo sostenible, por lo que las redes turísticas permiten incorporar un concepto amplio de medio ambiente (desde la gestión hotelera hasta la reutilización y reciclado de materiales, 
la señalización, los recorridos), la recuperación de valores tradicionales de nuestras comunidades primitivas o nuestro pasado cercano y la búsqueda de valores perdidos por parte de las comunidades (Ferreira, 2005).

Evidentemente, este proceso involucra una interrelación del sector y políticas públicas que incorporan estos objetivos y una mirada a largo plazo. Es aquí donde aparecen nuevos interrogantes, ċcómo se construyen redes sociales desde el turismo que contribuyan a la conservación del medio ambiente?, ccómo el mismo turismo puede iniciar un proceso de cambio a través de las redes? ¿de qué manera las actividades recreativas, deportivas o culturales se relacionan para la formación de de redes que demanden calidad ambiental? Estas preguntas, se asocian a la posible generación de redes sociales que van más allá de las campañas publicitarias y que apuntan a una visión holística del turismo que lleven otras formas de organización social, otros recursos y otras perspectivas.

Como resultado de la revisión de la evolución del turismo en el mundo, surge una nueva pregunta cipor qué adoptar las redes sociales en el subsector turístico con un enfoque lógico de carácter social formulado en el proyecto? Varias razones lo explican: en primer lugar, la política de gobierno que incorpora la ley 300 de 1996, denominada Ley General del Turismo, contemplada en el actual Plan de Desarrollo Económico, la cual formula incentivos al sector turismo, dándole la importancia y la trascendencia que el sector merece, estimulando la iniciativa privada y vinculando a las universidades, en calidad de asesores de entidades, que generan y mantienen trabajo, que pueden autorregularse, autogestionarse y autoevaluarse, con criterios autónomos y determinantes (Hair, 2004).

No obstante, ante la imposibilidad de que el sector se alimente con subvenciones de fondos públicos o de organizaciones estatales de ayuda para fomentar el turismo, se hace imprescindible crear las redes sociales que fomenten, faciliten y den a conocer los servicios turísticos, a fin de atraer a los turistas y les permita costear sus sostenimiento y eventual crecimiento y desarrollo (Cobra, 2000).

Otra razón, se origina de la creciente competencia entre los organizaciones que, en el ámbito internacional, nacional, regional y local, brindan este tipo de servicios, constituyéndose algunas veces, en monopolios, oligopolios o polipolios, lo que obliga a que las redes creen un sentido de pertenencia e identidad con el corredor, más allá de lograr el posicionamiento de los servicios que brinda (McDaniel, 2001). Una tercera, se deriva de los resultados arrojados, en la investigación en donde más del $85 \%$ de los usuarios estarían interesados en ofrecer servicios turísticos de una manera integrada, de tal forma, que les permita ampliar su cobertura y alcance, además de obtener un beneficio común.

A través de esta investigación, se presentaron limitaciones, principalmente en el proceso de obtención de información primaria, debido a la exigua disponibilidad de tiempo de los informantes. De la misma manera, se evidenció que solo existen los planes de desarrollo de los municipios en los que hacen alusión al desarrollo del turismo.

\section{CONCLUSIONES}

La presente investigación buscó fortalecer y diversificar la actividad turística, teniendo como referente esencial la creación de redes sociales de turismo, mediante aprovechamiento de los recursos turísticos en los municipios de La Calera y Sopó, lo que generó una oferta competitiva de servicios turísticos, en armonía con la diversidad natural, cultural y la creación de diferentes líneas de productos y servicios turísticos.

Mediante la investigación, se detectó que el turismo no refiere exclusivamente a una cuestión económica donde confluyen intereses de particulares o empresas privadas que buscan beneficios netamente económicos, sino que se consideraron, como aspectos fundamentales, los valores sociales y culturales que tiene estas comunidades, como medio de participación en el desarrollo del subsector turístico en dichos municipios.

La conformación de redes precisó que se deberán construir estrategias de integración entre estos dos municipios y sus comunidades, aprovechando sus potencialidades turísticas, eco-turísticas, antropológicas, naturales, históricas y culturales, entre otras, como parte integral para la conformación de un futuro corredor turístico, entre los municipios de La Calera y Sopó.

El proceso metodológico empleado proporcionó el conocimiento y el potencial que poseen los municipios para estimular y concientizar a las comunidades para que 
se asocien y crean redes turísticas y prestar los mejores servicios, aprovechando las ventajas competitivas de su patrimonio cultural, sus recursos naturales y su estratégica ubicación geográfica.

Se destaca la necesidad de aprovechar las riquezas naturales, los monumentos religiosos, las biodiversidad y el recurso humano para diversificar la oferta de servicios turísticos en los municipios de Sopó y La Calera, a través de las redes sociales que permitan valorar la cultura y la idiosincrasia de la comunidad, hasta ahora desaprovechada.

Se confía que este estudio abra nuevas posibilidades para responder a las preguntas relacionados con la creación y diseños de redes sociales con un enfoque turístico y de desarrollo empresarial, especialmente, en el énfasis ambiental, e impulse nuevos proyectos de investigación relacionados con las actividades empresariales turísticas, propias de nuestro país.

\section{BIBLIOGRAFÍA}

ABRAVEL, H. 1992. Cultura organizacional y autoridad simbólica. $2^{a}$ ed. Santa Fe de Bogotá: Serie empresarial LEGIS Editores. 255p.

BACCA URBINA, G. 2002. Evaluación de Proyectos. $3^{a}$ ed. Bogotá: Mac Graw-Hill. 150p.

BEJAR NAVARRO, R. 2007. El mexicano: aspectos culturales y psicosociales $7^{\mathrm{a}}$ ed. México: UNAM 209p.

CEBALLOS LASCOURAIN, H. 1998. Ecoturismo, Naturaleza y Desarrollo Sostenible. México. Diana. 150p.

COBRA, M. 2000. El Marketing de servicios, las estrategias para turismo, finanzas, salud y comunicación. México: Editorial Mc Graw Hill. 370p.

CHURCHIL, G. 2003. Investigación de Mercados. $4^{\mathrm{a}}$ ed. México: International Thomson Editores, 830p.

DEPARTAMENTO NACIONAL DE ESTADÍSTICA DANE. 2007. Directorio Temático de Turismo. Bogotá. El departamento. 300p.
FERREIRA, L.D. 2005. Estudo analítico das variáveis da macro envolvente de um destino turístico. Tékhne (Brasil). 4:135-147.

GUTIÉRREZ ROA, J. 2000. Recursos Naturales y Turismo. México DF: Ed. Limusa, 463p.

GUZMÁN, A. 2005. Inter. Cambios Grupo Chorlaví FIDAMERICA México: Mc Graw- Hill 320p.

HAIR, J. 2004. Investigación de Mercados $2^{\mathrm{a}}$ ed. México: Mc Graw Hill Interamericana Ed. 830p.

HERNÁNDEZ S., R. 2003. Metodología de la Investigación. $3^{a}$ ed. México: Mc Graw- Hill, 705p.

JANY, N.J. 2001. Investigación Integral de Mercados: Un enfoque para el siglo 21. $2^{\mathrm{a}}$ ed. Santafé de Bogotá. D.C.: Editorial Mc Graw Hill, 409p.

LAMB, C.W.; HAIR, J. 2006. Marketing. Estados Unidos de Norte América: Cengage Learning Editores, 689p.

LOMMITZ, L.A. 1994. Redes sociales y poder: ensayos de antropología. México: FLACSO. 373p.

MINISTERIO DO TURISMO DO BRASIL. 2005. Turismo no Brasil- um guia para o guia: SENAC. 178p.

MCDANIEL, C. 2001. Investigación de Mercados Contemporánea. $4^{a}$ ed. Bogotá: Internacional Thomson Editores. 780p

MAZÓN, T. 2001. Sociología del turismo. Madrid: Centro de Estudios Ramón Arces. 109p.

NEWSOME, D. 2002. Natural area tourism. Ecology, impact and management. Aspects of tourismo. Channel View Publications. Clevedon BuffeloToronto-Sydney. 450p.

NUÑEZ DEL PRADO BENAVENTE, A. 2000. Estadística para planificación. $8^{\mathrm{a}}$ ed. Bogotá: Siglo veintiuno. 234p.

OSPINA, B.E.; SANDOVAL, J.J.; ARISTIZABAL, C.A.; RAMÍREZ, M.C. 2005. La escala de Likert en la evaluación de los conocimientos y las actitudes 
de los profesionales de la salud. Antioquia 2003. Investigación Educ. Enferm. 23(1):14-29.

PABLOS T., E. 2001. Mujeres en las fronteras: trabajo salud y migración. México: Plaza y Valdés. 333p.

PÉREZ DE LAS HERAS, M. 2004. Manual de turismo sostenible: como conseguir un turismo social, económico y ambientalmente sostenible. $2^{\text {a }}$ ed. España: Ediciones Mundo Prensa. 284p.
RITZER, G. 2001. Economía y Sociedad: esbozo de Sociología Comprensiva. $3^{a}$ ed. Madrid: ed. McGraw Hill. 660p.

SOARES, E.; BRITO, C.; CAVALCANTI, M. 2006. Perfil vocal do guía de turismo. Rev Cefac. 8(4):501508.

Recibido: Enero 17 de 2008

Aceptado: Mayo 18 de 2008 